BMJ Open Diabetes Research $\&$ Care

\section{Inappropriate intensification of glucose- lowering treatment in older patients with type 2 diabetes: the global DISCOVER study}

To cite: Bongaerts $B$, Arnold SV, Charbonnel BH, et al. Inappropriate intensification of glucose-lowering treatment in older patients with type 2 diabetes: the global DISCOVER study. BMJ Open Diab Res Care 2021;9:e001585. doi:10.1136/ bmjdrc-2020-001585

- Supplemental material is published online only. To view, please visit the journal online (http://dx.doi.org/10.1136/ bmjdrc-2020-001585).

Received 18 May 2020 Revised 25 March 2021 Accepted 2 April 2021
Check for updates

(c) Author(s) (or their employer(s)) 2021. Re-use permitted under CC BY-NC. No commercial re-use. See rights and permissions. Published by BMJ.

For numbered affiliations see end of article.

Correspondence to Dr Brenda Bongaerts; Brenda.Bongaerts@ddz.de

\section{ABSTRACT}

Introduction Although individualized target glycated hemoglobin $\left(\mathrm{HbA}_{1 \mathrm{c}}\right)$ levels are recommended in older people with type 2 diabetes, studies report high levels of potential overtreatment. We aimed to investigate the proportion of older patients (aged $\geq 65$ years) who potentially received an inappropriately intensive treatment $(\mathrm{HbA}$ lc level $<7.0 \%(53.0 \mathrm{mmol} / \mathrm{mol})$ ) in a global study. Factors associated with intensive glycemic management and using glucose-lowering medications associated with a high risk of hypoglycemia (high-risk medications (insulin, sulfonylureas, and meglitinides)) were also assessed.

Research design and methods DISCOVER is a 3-year observational study program of 15992 people with type 2 diabetes initiating second-line glucose-lowering therapy in 38 countries. Data were collected at baseline (initiation of second-line therapy) and at 6, 12, and 24 months. Factors associated with an inappropriately intensive treatment or using high-risk medications were assessed using a hierarchical regression model.

Results Of the 3344 older patients with baseline $\mathrm{HbA}_{1 \mathrm{c}}$ data in our analytic cohort, $23.5 \%$ received inappropriate treatment intensification. Among those who had follow-up $\mathrm{HbA}_{1 \mathrm{c}}$ data, $55.2 \%, 54.2 \%$, and $53.5 \%$ were inappropriately tightly controlled at 6,12 , and 24 months, respectively, with higher proportions in highincome than in middle-income countries. The proportion of patients receiving high-risk medications was higher in middle-income countries than in high-income countries. Gross national income (per US\$5000 increment) was associated with increased odds of inappropriately intensive treatment but with decreased odds of receiving high-risk medications.

Conclusions A large proportion of older DISCOVER patients received an inappropriately intensive glucoselowering treatment across the 2 years of follow-up, with substantial regional variation. The use of high-risk medications in these patients is particularly concerning.

\section{INTRODUCTION}

Guidelines generally recommend a glycated hemoglobin $\left(\mathrm{HbA}_{1 \mathrm{c}}\right)$ target level of $\leq 7.5 \%$

\section{Significance of this study}

What is already known about this subject?

- Studies from high-income countries, such as the USA and the UK, show that a high proportion of older patients (aged $\geq 65$ years) with type 2 diabetes are potentially overtreated (glycated hemoglobin $\left(\mathrm{HbA}_{1 \mathrm{c}}\right)$ level $<7.0 \%$ $(53.0 \mathrm{mmol} / \mathrm{mol}))$ in routine clinical practice.

What are the new findings?

- We found that although gross national income (per US\$5000 increment) was associated with greater odds of an inappropriately intensive treatment, participants from lower-middle-income and upper-middle-income countries had greater odds of receiving high-risk glucose-lowering medication than those from highincome countries.

- Almost a quarter of older DISCOVER patients (aged $\geq 65$ years) received inappropriate treatment intensification $(\mathrm{HbA}$ level $<7.0 \%(53.0 \mathrm{mmol} / \mathrm{mol}))$ at baseline (initiation of second-line glucose-lowering treatment); for approximately half of the patients, treatment was inappropriately intensified during follow-up.

How might these results change the focus of research or clinical practice?

- Our findings demonstrate the need for a more personalized approach to treatment of type 2 diabetes, particularly among older patients from lower-middle-income and upper-middle-income countries.

(53.0 mmol $/ \mathrm{mol})$ in otherwise healthy older (aged $\geq 65$ years) people with type 2 diabetes ${ }^{1-3}$ and an $\mathrm{HbA}_{1 \mathrm{c}}$ level of $\leq 8.5 \%$ in older individuals with complex comorbidities. An $\mathrm{HbA}_{1 \mathrm{c}}$ level target of $>7.5 \%$ may therefore be more appropriate in some older patients ${ }^{1-7}$ because they are at an increased risk of hypoglycemic events ${ }^{8}$ and related complications, including falls, ${ }^{9}$ fractures, ${ }^{9}$ cognitive impairment, ${ }^{10}$ vascular complications, ${ }^{11}$ and increased 
mortality. ${ }^{12}$ Stringent $\mathrm{HbA}_{1 \mathrm{c}}$ targets to control type 2 diabetes and diabetes-related complications in older individuals often result in complex treatment regimens, leading to an increased risk of polypharmacy (most commonly described as concomitant use of five or more medications), which has been linked to adverse drug events, drug-drug interactions, prescribing cascades, and in some cases poor treatment adherence. ${ }^{13}$ With this in mind, guidelines suggest an individualized treatment approach in older patients, with a focus on simple treatment regimens and glucose-lowering drugs that have a low risk of hypoglycemia, such as metformin, dipeptidyl peptidase-4 (DPP-4) inhibitors, glucagon-like peptide-1 (GLP-1) receptor agonists, and sodium glucose cotransporter 2 (SGLT-2) inhibitors. ${ }^{17814}$

Studies from Europe and the USA suggest that these guidelines are not always followed in clinical practice, with high proportions of older patients potentially being overtreated (patients aged $\geq 65$ years with an $\mathrm{HbA}_{1 \mathrm{c}}$ level of $<7.0 \%(53.0 \mathrm{mmol} / \mathrm{mol})) .{ }^{14-18}$ This may partially explain the high number of hospitalizations for hypoglycemia among older patients from high-income countries. ${ }^{19}$ There is currently lack of available data on the inappropriate intensification of treatment of patients with type 2 diabetes from low-income and middle-income countries.

In order to fill this knowledge gap, we used data from the DISCOVER study program-a 3-year global prospective, observational study program investigating clinical outcomes, health-related quality of life, and treatment patterns in individuals with type 2 diabetes initiating second-line glucose-lowering therapy in 38 countries across 6 continents ${ }^{2021}$ - to assess the prevalence of, and factors associated with, an inappropriately intensive treatment of older patients during the first 24 months of the study.

\section{METHODS}

\section{Research design}

The methods of the DISCOVER study program have been described in detail elsewhere. ${ }^{20}{ }^{21}$ In brief, the DISCOVER study program comprises two similar 3-year non-interventional, prospective, observational studies of 15992 patients with type 2 diabetes initiating second-line glucose-lowering therapy across 38 countries (DISCOVER (NCT02322762) in 37 countries and J-DISCOVER (NCT02226822) in Japan). ${ }^{20}{ }^{21}$ Countries participating in the DISCOVER study are as follows: Algeria, Argentina, Australia, Austria, Bahrain, Brazil, Canada, China, Colombia, Costa Rica, Czech Republic, Denmark, Egypt, France, India, Indonesia, Italy, Japan, Jordan, Kuwait, Lebanon, Malaysia, Mexico, the Netherlands, Norway, Oman, Panama, Poland, Russia, Saudi Arabia, South Africa, South Korea, Spain, Sweden, Taiwan, Tunisia, Turkey, and the United Arab Emirates. In line with the non-interventional nature of the study, the protocol did not mandate the use of specific drugs. Treatment decisions were made by physicians, as they would be in routine clinical practice.

\section{Patient enrollment}

Patients were enrolled in DISCOVER from December 2014 to June 2016 and in J-DISCOVER from September 2014 to December 2015. To ensure that data were as reflective of routine clinical practice as possible, inclusion and exclusion criteria were kept to a minimum. Briefly, patients aged $\geq 18$ years who were initiating second-line glucose-lowering therapy (defined as adding a glucoselowering drug or switching between therapies) were eligible for inclusion, provided that they were not pregnant, were not undergoing dialysis, and had no history of renal transplant, and if their first-line therapy was not an injectable agent, or a herbal remedy or natural medicine alone. Whereas J-DISCOVER enrolled only patients who were receiving oral monotherapy as first-line treatment, DISCOVER enrolled patients who were receiving any type of oral therapy (one or more oral agents, or a fixed-dose combination). Full inclusion and exclusion criteria are shown in online supplemental table 1. All eligible patients were invited to participate in the study by their physician and provided written informed consent. A list of participating investigators can be found in online supplemental appendix list 1 .

\section{Data collection}

Data from China $(n=1293)$ were not included because they were not available at the time of publication owing to governance reasons. Data were collected at baseline (initiation of second-line glucose-lowering therapy) and at 6,12 , and 24 months within a 4-month window $( \pm 2$ months) to reflect patient visits in routine clinical practice. Data were captured by the treating physician using a standardized electronic case report form (eCRF). Some data were extracted from existing electronic health records in Canada, Denmark, France, Norway, and Sweden. In these countries, data not routinely captured in electronic medical records, such as the reason(s) for treatment change, were obtained by the investigators using a questionnaire that was linked back to patients' medical records. Data collected at baseline and during follow-up included the following: patient demographics (such as sex, age, body mass index (BMI), and duration of type 2 diabetes); clinical variables (such as $\mathrm{HbA}_{1 c}$ levels); and first-line and second-line glucose-lowering treatments. First-line and second-line therapy refers to a patient's first ever treatment regimen for type 2 diabetes (before study entry) and second treatment regimen (at study baseline), respectively. Treatment at each follow-up visit was recorded because participants may have changed treatment at other routine clinical visits not recorded as part of DISCOVER. Clinical variables were measured in accordance with routine clinical practice, and data collection for these variables was not mandatory.

Gross national income (GNI) per capita in the DISCOVER countries in 2015 was sourced from the 
World Bank using the Atlas method (online supplemental figure 1$).{ }^{6}$ The Atlas conversion factor uses a country's exchange rate for the current and preceding 2 years, adjusted for the difference between the rate of inflation in that country and international inflation.

\section{Statistical analyses}

Our analytic cohort comprised older participants (aged $\geq 65$ years) with an available baseline $\mathrm{HbA}_{1 \mathrm{c}}$ measurement $(\mathrm{N}=3344) .{ }^{22}$ Inappropriately intensive glucose-lowering treatment was defined (cross-sectionally) as participants having an $\mathrm{HbA}_{1 \mathrm{c}}$ level of $<7.0 \%(53.0 \mathrm{mmol} / \mathrm{mol})$ at the time of data collection at baseline, and at 6,12 , and 24 months after baseline. Insulin, sulfonylureas, and meglitinides were considered medications associated with a high risk of hypoglycemia (high-risk glucose-lowering medications). It is important to note that, while there is no formal definition of inappropriate tight glycemic management in older individuals with type 2 diabetes, our definition is in line with other published studies and is in agreement with the current American Diabetes Association (ADA) guidelines. ${ }^{1823}$

Exploratory variables are presented as numbers (percentages), mean (SD), and median (IQR), as appropriate. $\mathrm{P}$ values were calculated, as a measure of statistical significance, using Student's t-test (continuous variables), $\chi^{2}$ test (categorical variables), or Fisher's exact test (categorical variables). $\mathrm{P}$ values $<0.05$ were considered statistically significant.

Factors associated with having an $\mathrm{HbA}_{1 \mathrm{c}}$ level of $<7.0 \%$ $(53.0 \mathrm{mmol} / \mathrm{mol})$ at 12 months were assessed using a hierarchical regression model with country as a random effect, and with baseline covariates (sex, age, BMI, time since diabetes diagnosis, GNI, and medical history (microvascular complications, macrovascular complications, and chronic kidney disease)) as well as treatment with highrisk glucose-lowering medications at 12 months as fixed effects. A similar model was used to assess the factors associated with use of high-risk glucose-lowering medications at 12 months, with country as a random effect and with the aforementioned baseline covariates and $\mathrm{HbA}_{1 \mathrm{c}}$ level at 12 months as fixed effects. Multiple imputation was used to account for unreported data, which used iterative sequential regression to sample missing values from the predictive distribution of each variable, conditional to all other variables. Variables included in the imputation model were the dependent variables $\left(\mathrm{HbA}_{1 \mathrm{c}}\right.$ level or use of high-risk medication); all the independent variables (patient demographics (such as sex, age, BMI, and duration of type 2 diabetes), clinical variables (such as $\mathrm{HbA}_{1 \mathrm{c}}$ levels), and first-line and second-line glucose-lowering treatments); and country. Ten randomly imputed data sets were generated in this way. Analyses were replicated on each imputed data set and the model estimates were pooled across imputations using Rubin's rules. All statistical analyses were performed using the SAS V.9.4 statistical software system.

\section{RESULTS}

Among the 14699 DISCOVER participants, 11891 $(80.9 \%)$ had an $\mathrm{HbA}_{1 \mathrm{c}}$ measurement at baseline. Our analytic cohort comprised 3344 patients (28.1\%) aged $\geq 65$ years. At baseline, when initiating second-line glucose-lowering therapy, $785(23.5 \%)$ patients aged $\geq 65$ years had an $\mathrm{HbA}_{1 \mathrm{c}}$ level of $<7.0 \%(53.0 \mathrm{mmol} / \mathrm{mol}$; figure 1). Of these potentially inappropriately intensified patients, $252(32.1 \%)$ received second-line treatment with high-risk glucose-lowering medications (figure 1A). Baseline characteristics were similar between patients with $\mathrm{HbA}_{1 \mathrm{c}}$ levels of $<7.0 \%$ or $\geq 7.0 \%(53.0 \mathrm{mmol} / \mathrm{mol})$ at 12 months (table 1 ).

Follow-up data at 6, 12, and 24 months were available for 2431 (72.7\%), 2578 (77.1\%), and 2465 (73.7\%) older patients, respectively. An $\mathrm{HbA}_{1 \mathrm{c}}$ level of $<7.0 \%$ (53.0 $\mathrm{mmol} / \mathrm{mol}$ ) was noted in $1343(55.2 \%), 1398$ (54.2\%), and $1320(53.5 \%)$ patients at 6, 12, and 24 months, respectively (figure 1A). Among patients with $\mathrm{HbA}_{1 \mathrm{c}}$ levels of $<7.0 \%(53.0 \mathrm{mmol} / \mathrm{mol})$, high-risk glucoselowering medications were prescribed in $474(35.4 \%)$, $495(36.0 \%)$, and $462(36.1 \%)$ patients at 6,12 , and 24 months, respectively (figure 1A).

The proportion of patients with an $\mathrm{HbA}_{1 \mathrm{c}}$ level of $<7.0 \%$ $(53.0 \mathrm{mmol} / \mathrm{mol})$ varied between lower-middle-income, upper-middle-income, and high-income countries (figure 1B-D). Whereas the proportion of patients with an $\mathrm{HbA}_{1 \mathrm{c}}$ level of $<7.0 \%(53.0 \mathrm{mmol} / \mathrm{mol})$ was highest in high-income countries, the proportion of patients receiving treatment with high-risk glucose-lowering medications was highest in middle-income countries at all time points.

In the hierarchical regression model, patients with a longer duration of diabetes and those who were prescribed treatment with high-risk glucose-lowering medications, at the time of their 12-month visit, had decreased odds of having an $\mathrm{HbA}_{1 \mathrm{c}}$ level of $<7.0 \%$ (53.0 $\mathrm{mmol} / \mathrm{mol}$ ) (figure 2). Country income (GNI per US $\$ 5000$ increment) was associated with increased odds of a patient having an $\mathrm{HbA}_{1 \mathrm{c}}$ level of $<7.0 \%(53.0 \mathrm{mmol} /$ mol) at 12 months.

The proportion of patients receiving treatment with sulfonylureas at 12 months was significantly lower in patients with an $\mathrm{HbA}_{1 \mathrm{c}}$ level of $<7.0 \%(53.0 \mathrm{mmol} / \mathrm{mol}$; $29.5 \%$ ) than in those with an $\mathrm{HbA}_{1 \mathrm{c}}$ level of $\geq 7.0 \%$ (53.0 $\mathrm{mmol} / \mathrm{mol}$; $42.4 \%$ ) (table 1 ). Similarly, the proportion of patients receiving treatment with insulin at 12 months was also significantly lower in patients with an $\mathrm{HbA}_{1 \mathrm{c}}$ level of $<7.0 \%(53.0 \mathrm{mmol} / \mathrm{mol} ; 2.3 \%)$ than in those with an $\mathrm{HbA}_{1 \mathrm{c}}$ level of $\geq 7.0 \%(53.0 \mathrm{mmol} / \mathrm{mol} ; 10.9 \%)$ (table 1$)$.

In the multivariable model, high BMI at baseline (per $5 \mathrm{~kg} / \mathrm{m}^{2}$ increment), 12-month $\mathrm{HbA}_{1 \mathrm{c}}$ level of $<7.0 \%$ (53.0 $\mathrm{mmol} / \mathrm{mol}$, vs $\geq 7.0 \%$ ), and shorter duration of type 2 diabetes were associated with decreased odds of being treated with high-risk glucose-lowering medication (figure 3). Country income (GNI per US\$5000 increment) was also associated with decreased odds of being 
Patients using high-risk glucose-lowering medications

Patients with missing medication data

A. Overall

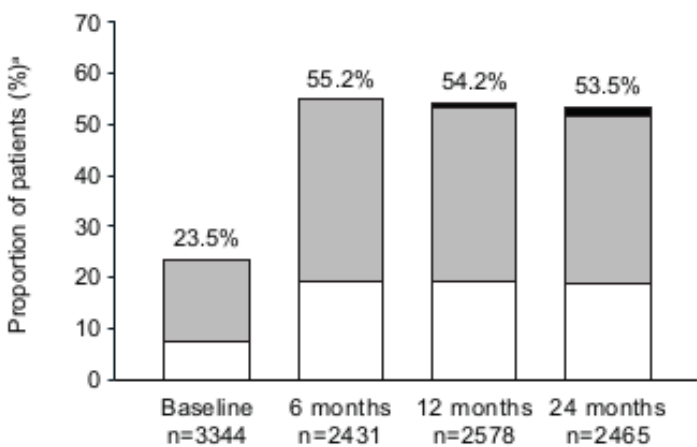

C. Upper-middle-income countries (GNI)

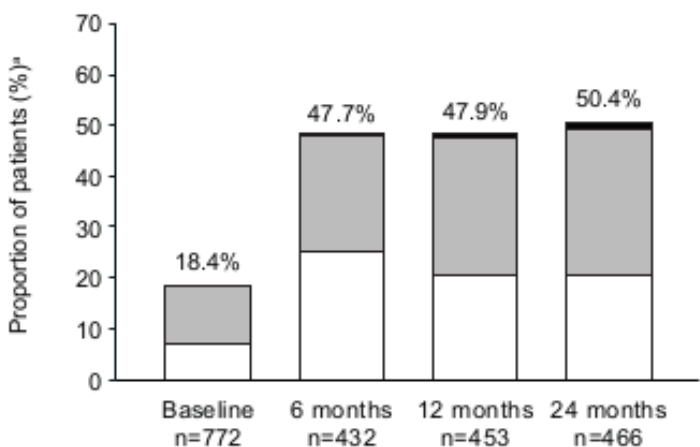

Patients not using high-risk glucose-lowering medications

B. Lower-middle-income countries (GNI)

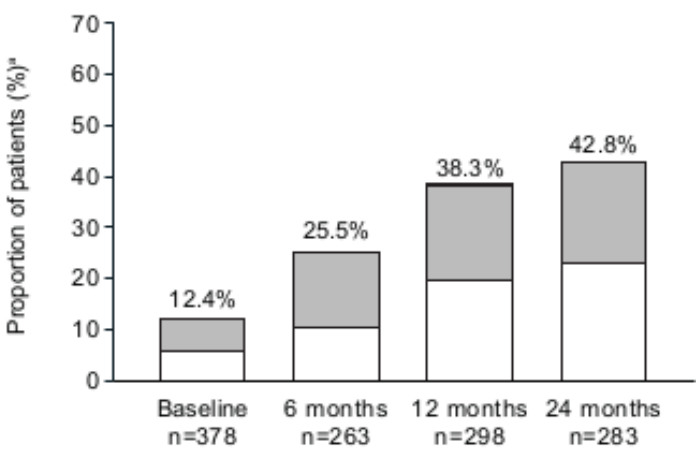

D. High-income countries (GNI)

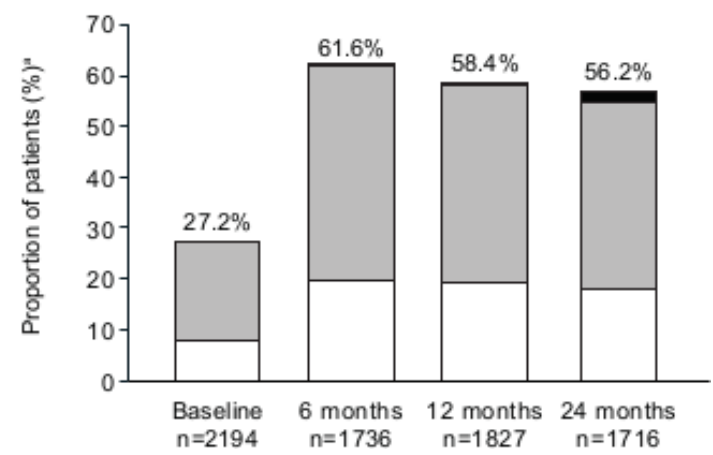

Figure 1 Proportion of older patients (aged $\geq 65$ years) with $\mathrm{HbA}_{1 \mathrm{c}}$ level of $<7.0 \%$ treated with or without high-risk glucoselowering medications (insulin, sulfonylureas, and/or meglitinides): (A) overall, (B) lower-middle-income countries (GNI: US\$1005-US\$3955), (C) upper-middle-income countries (GNI: US\$3956-US\$12 235), and (D) high-income countries (GNI: 2US\$12 236). This analysis included older patients with treatment information available at baseline and at 6, 12, and 24 months. ${ }^{a}$ Patients aged $\geq 65$ years and had an $\mathrm{HbA}_{1 \mathrm{c}}$ level of $<7.0 \%$. GNI, gross national income; $\mathrm{HbA}_{1 \mathrm{c}}$, glycated hemoglobin.

treated with high-risk glucose-lowering medications at 12 months.

\section{CONCLUSIONS}

In an observational analysis of a large global cohort of patients with type 2 diabetes, we found that a quarter of older participants had an $\mathrm{HbA}_{1 c}$ level of $<7.0 \%(53.0$ $\mathrm{mmol} / \mathrm{mol}$ ) at baseline and approximately half of participants had an $\mathrm{HbA}_{1 c}$ level of $<7.0 \%(53.0 \mathrm{mmol} / \mathrm{mol})$ during follow-up. The overall increase in the proportion of patients receiving inappropriately intensive treatment could be explained, in part, by the fact that all DISCOVER participants were initiating second-line glucose-lowering therapy (defined as add-on or switching), which may result in a decrease in the overall mean $\mathrm{HbA}_{1 c}$ level between baseline and 6 months. Thereafter, the proportion of participants for whom therapy was inappropriately tight remained high, possibly because some physicians failed to recognize inappropriate intensification and adapt treatment accordingly.

The proportion of patients who were overly intensively treated varied across countries in all income brackets. A novel finding was that patients in high-income countries were more likely to have intensive glycemic control, potentially reflecting stricter treatment regimens, with a greater emphasis placed on glucose monitoring and achieving glycemic targets, and better access to healthcare. The increased prevalence of baseline vascular complications in patients from high-income countries, compared with patients from lower-middle-income countries seen in a previous analysis of DISCOVER data, ${ }^{11}$ may also play a part in driving the high rate of inappropriately intensively treated diabetes, with a focus on ensuring that these patients achieve good glycemic control to minimize their risk of diabetes-related vascular complications. Intensive glycemic control and the presence of comorbidities that require medical treatment may place some patients at an increased risk of polypharmacy, with low $\mathrm{HbA}_{1 \mathrm{c}}$ levels only achieved, in some cases, through the use of multiple glucose-lowering medications. In the USA, $57 \%$ of women and $59 \%$ of men reported using more than five different medications on a weekly basis, with older adults with type 2 diabetes at high risk of polypharmacy. ${ }^{13}$ Similarly, in Italy, $51.7 \%$ of older individuals (aged $\geq 65$ years) with type 2 diabetes were reported to have polypharmacy, with comorbidities and diabetesrelated complications shown to be associated with increased risk of polypharmacy. ${ }^{24}$

At each time point, approximately one-third of overly intensively controlled patients received a 
Table 1 Characteristics of DISCOVER study patients aged $\geq 65$ years, according to $\mathrm{HbA}$ lc level after 12 months of follow-up

\begin{tabular}{|c|c|c|c|c|}
\hline & \multirow{2}{*}{$\begin{array}{l}\text { Overall } \\
\mathrm{n}=2578\end{array}$} & \multicolumn{3}{|c|}{$\mathrm{HbA}_{1 \mathrm{c}}$ level after 12 months of follow-up } \\
\hline & & $\mathrm{HbA}_{1 \mathrm{c}}<7.0 \% \mathrm{n}=1398$ & $\mathrm{HbA}_{1 \mathrm{c}} \geq 7.0 \% \mathrm{n}=1180$ & P value* \\
\hline Sex, male, n (\%) & $1422(55.2)$ & $788(56.4)$ & $634(53.8)$ & 0.188 \\
\hline Missing, $n$ & 3 & 1 & 2 & \\
\hline Age, years, mean (SD) & $72.2(5.5)$ & $72.4(5.5)$ & $71.9(5.5)$ & 0.042 \\
\hline $\mathrm{HbA}_{1 \mathrm{c}}$ level at baseline, $\%$, mean (SD) & $7.8(1.3)$ & $7.4(1.2)$ & $8.3(1.3)$ & $<0.001$ \\
\hline $\mathrm{BMI}, \mathrm{kg} / \mathrm{m}^{2}$, mean $(\mathrm{SD})$ & $24.6(4.3)$ & $24.4(4.3)$ & $25.1(4.2)$ & 0.018 \\
\hline Missing, $n$ & 1777 & 884 & 893 & \\
\hline \multicolumn{5}{|l|}{ Country GNI, $n$} \\
\hline Lower-middle & 298 & 114 & 184 & $<0.001$ \\
\hline Upper-middle & 453 & 217 & 236 & $<0.001$ \\
\hline High & 1827 & 1067 & 760 & $<0.001$ \\
\hline Time since diagnosis, years, mean (SD) & $7.8(6.4)$ & $7.4(6.2)$ & $8.3(6.4)$ & $<0.001$ \\
\hline Missing, $\mathrm{n}$ & 109 & 66 & 43 & \\
\hline \multicolumn{5}{|l|}{ Medical history, n (\%) } \\
\hline Macrovascular complications & $676(26.3)$ & $370(26.6)$ & $306(26.0)$ & 0.712 \\
\hline Missing, $n$ & 10 & 8 & 2 & \\
\hline Microvascular complications & $759(29.5)$ & $406(29.1)$ & 353 (29.9) & 0.661 \\
\hline Missing, $n$ & 4 & 4 & & \\
\hline Chronic kidney disease & $323(12.5)$ & $192(13.8)$ & $131(11.1)$ & 0.041 \\
\hline Missing, $n$ & 4 & 4 & 0 & \\
\hline \multicolumn{5}{|l|}{ First-line treatment $\dagger, \mathrm{n}(\%)$} \\
\hline Metformin & $1699(65.9)$ & $872(62.4)$ & $827(70.1)$ & $<0.001$ \\
\hline DPP-4 inhibitors & $559(21.7)$ & $309(22.1)$ & $250(21.2)$ & 0.573 \\
\hline Sulfonylureas & $488(18.9)$ & $204(14.6)$ & $284(24.1)$ & $<0.001$ \\
\hline$\alpha$-glucosidase inhibitors & $85(3.3)$ & $58(4.1)$ & $27(2.3)$ & 0.008 \\
\hline Meglitinides & $62(2.4)$ & $31(2.2)$ & $31(2.6)$ & 0.498 \\
\hline SGLT-2 inhibitors & $26(1.0)$ & $13(0.9)$ & $13(1.1)$ & 0.663 \\
\hline Thiazolidinediones & $60(2.3)$ & $35(2.5)$ & $25(2.1)$ & 0.518 \\
\hline \multicolumn{5}{|l|}{ Treatment at 12 months $\dagger, \mathrm{n}(\%)$} \\
\hline Metformin & $1680(66.7)$ & $866(63.0)$ & $814(71.3)$ & $<0.001$ \\
\hline DPP-4 inhibitors & $1514(60.2)$ & $861(62.6)$ & $653(57.2)$ & 0.005 \\
\hline Sulfonylureas & $889(35.3)$ & 405 (29.5) & $484(42.4)$ & $<0.001$ \\
\hline$\alpha$-glucosidase inhibitors & $145(5.8)$ & $89(6.5)$ & $56(4.9)$ & 0.092 \\
\hline GLP-1 receptor agonists & $68(2.7)$ & $41(3.0)$ & $27(2.4)$ & 0.341 \\
\hline Meglitinides & $143(5.7)$ & $73(5.3)$ & $70(6.1)$ & 0.375 \\
\hline SGLT-2 inhibitors & $259(10.3)$ & $134(9.7)$ & $125(10.9)$ & 0.323 \\
\hline Thiazolidinediones & $242(9.6)$ & $134(9.7)$ & $108(9.5)$ & 0.806 \\
\hline Insulin & $157(6.2)$ & $32(2.3)$ & 125 (10.9) & $<0.001$ \\
\hline Missing & 61 & 23 & 38 & \\
\hline
\end{tabular}

Percentages were calculated for all patients with data available; patients with missing data were excluded.

${ }^{*} \mathrm{P}$ value was calculated using Student's t-test.

†Treatment categories are not mutually exclusive, and each category includes monotherapies and combination therapies.

BMI, body mass index; DPP-4, dipeptidyl peptidase-4; GLP-1, glucagon-like peptide-1; GNI, gross national income; $\mathrm{HbA}_{1 \mathrm{c}}$, glycated

hemoglobin; SGLT-2, sodium glucose cotransporter 2. 


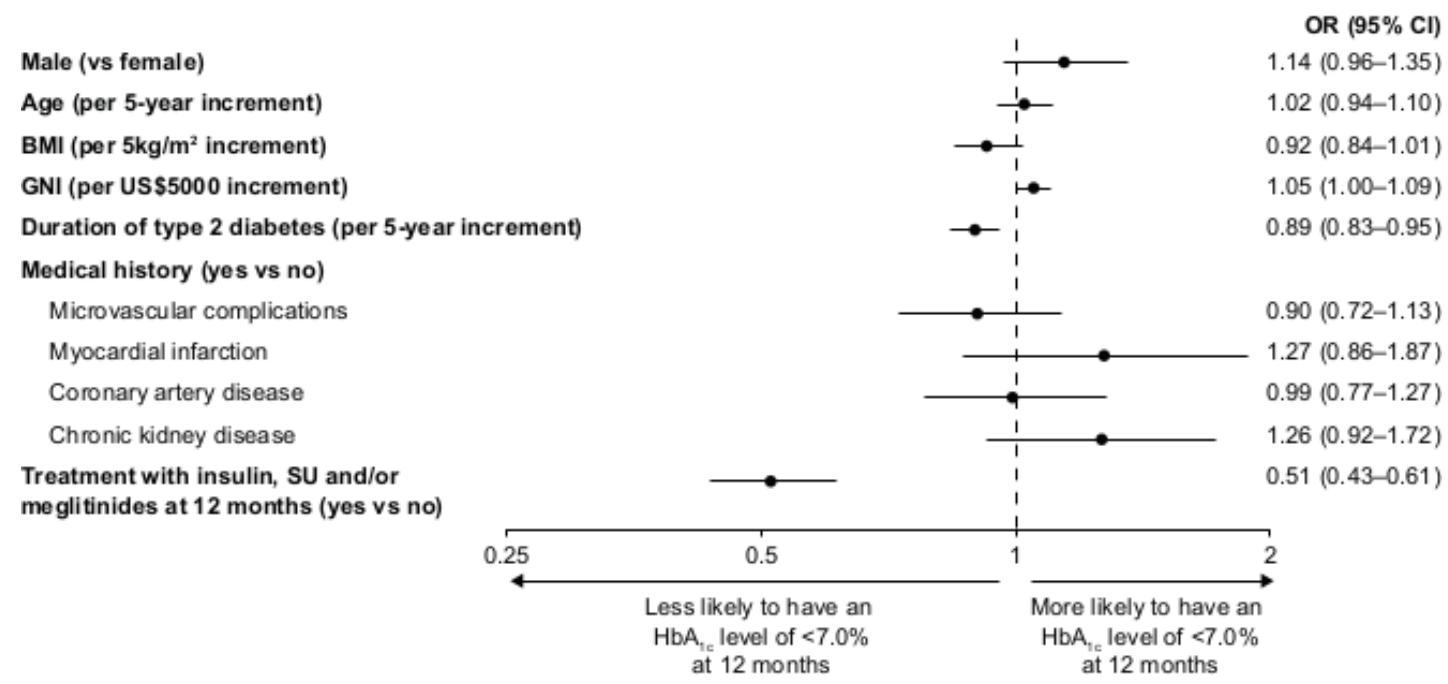

Figure 2 Baseline factors associated with odds of having $\mathrm{HbA}_{1 \mathrm{c}}$ level of $<7.0 \%$ at 12 months of follow-up. OR was calculated using hierarchical logistic model, adjusted for baseline covariates and treatment at 12 months of follow-up, with country as a random effect. BMI, body mass index; GNI, gross national income; $\mathrm{HbA}_{10}$, glycated hemoglobin; SU, sulfonylurea.

glucose-lowering treatment associated with a high risk of hypoglycemia. However, patients in lower-middle-income and upper-middle-income countries were more likely to use medications with a high risk of hypoglycemia. This may be indicative of the limited availability and affordability of alternative glucose-lowering therapies, such as DPP-4 inhibitors, GLP-1 receptor agonists, and SGLT-2 inhibitors, in middle-income countries. ${ }^{25-27}$ As such, there seems to be a substantial global opportunity for quality improvement by adopting a personalized treatment approach to decrease the risk of hypoglycemia in older patients with type 2 diabetes.

Our findings are in line with a previous study in the USA in which half of the participants with type 2 diabetes who were aged $\geq 75$ years were prescribed therapies associated with a high risk of hypoglycemia, despite having an $\mathrm{HbA}_{1 \mathrm{c}}$ level of $<7.0 \%(53.0 \mathrm{mmol} / \mathrm{mol}) .{ }^{15} 18$ A similar study in the UK found that $35.7 \%$ of people with type 2 diabetes aged $\geq 70$ years were prescribed either insulin or a sulfonylurea; of these individuals, one-third had an $\mathrm{HbA}_{1 c}$ level of $<7.0 \%(53.0 \mathrm{mmol} / \mathrm{mol}) .{ }^{16}$ Finally, the Guideline Adherence to Enhance Care (GUIDANCE) study of people aged $>65$ years with type 2 diabetes in eight European countries found that $44.7 \%$ of patients were prescribed either insulin or a sulfonylurea despite having an $\mathrm{HbA}_{1 c}$ level of $<7.0 \%(53.0 \mathrm{mmol} / \mathrm{mol}) .{ }^{17}$ In addition, these studies were all conducted in either Europe or the USA and are therefore not representative of a global population. Our study extends these previous findings to a global cohort of patients from countries with varied income levels.

Male (vs female)
Age (per 5-year increment)
BMI (per $5 \mathrm{~kg} / \mathrm{m}^{2}$ increment)
GNI (per US $\$ 5000$ increment)
Duration of type 2 diabetes (per 5 -year increment)
Medical history (yes vs no)
Microvascular complications
Myocardial infarction
Coronary artery disease
Chronic kidney disease
HbA $\mathrm{A}_{1 \mathrm{c}}$ level at 12 months of follow-up (vs $\geq 7.0 \%$ )
HbA $\mathrm{A}_{\mathrm{tc}}$ level $<7.0 \%$
Missing

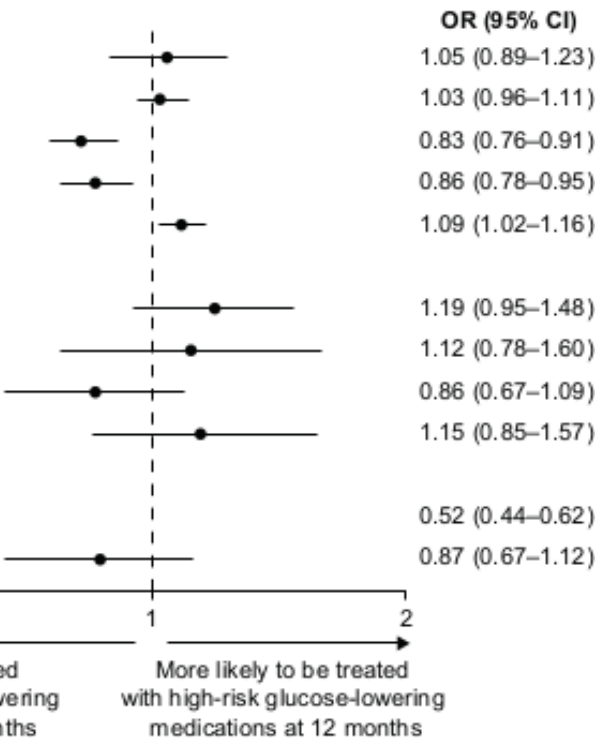

Figure 3 Baseline factors associated with odds of being treated with insulin, sulfonylureas, and/or meglitinides at 12 months. Data on treatment regimen at 12 months were available for 2980 patients. OR was calculated using hierarchical logistic model, adjusted for baseline covariates and $\mathrm{HbA}_{1 \mathrm{c}}$ level at 12 months of follow-up, with country as a random effect. BMl, body mass index; GNI, gross national income; $\mathrm{HbA}_{1 c}$, glycated hemoglobin. 
Our results, in combination with those of previous studies, indicate that many older patients are still potentially being inappropriately tightly controlled. ${ }^{15-17}$ These individuals may thus be at an increased risk of polypharmacy, with adherence to stringent glycemic targets requiring treatment with multiple glucose-lowering medications. ${ }^{13}$ The addition of multiple glucose-lowering medications to the treatment regimen of older individuals is associated with an increased risk of drugdrug interactions and other adverse events. ${ }^{28}$ The use of glucose-lowering medications that are associated with hypoglycemia in a substantial proportion of these patients is of particular concern. Data from previous studies have shown severe hypoglycemia to be a common cause of hospitalization among older individuals with type 2 diabetes, with the proportion of individuals hospitalized for hypoglycemia exceeding that of hyperglycemia. ${ }^{29}{ }^{30}$ Given the association between inappropriately intensive treatment and risk of hypoglycemia, there may be a need for some physicians to consider treatment regimen simplification (discontinuation of at least one glucose-lowering agent or a reduction in dosage) in some older patients, as per the current ADA guidelines. ${ }^{1}$ The benefits and risks of different combinations of glucoselowering therapies, in combination with medications for associated comorbidities, must be weighed and discussed with the individual and/or caregiver. ${ }^{13}$ Primary healthcare practitioners may also benefit from education on how to recognize and manage potentially inappropriate treatment intensifications in older patients. Too tightly controlled glycemia may also result from, at least in part, variables we were unable to measure, such as physician preference and experience, medication costs and availability, and number of physician visits. However, without studying the long-term effects of inappropriate treatment intensification on patient outcomes, our data do not support treatment de-intensification in these patients.

The primary strengths of the DISCOVER study program are both the large number of patients enrolled and the range of treatment sites and countries included, some of which have rarely been studied before. Data collection with a standardized eCRF allowed for the comparison of results between countries and regions. The observational nature of DISCOVER provided an ideal setting to investigate global treatment patterns, with minimal external influence and all treatment decisions made by the physician, as in routine clinical practice. However, our results must be interpreted with several limitations in mind. Although DISCOVER sites were selected to optimize diversity in each country, it is unclear if our findings truly reflect the quality of care within each country or can be generalized outside of the countries and regions included in the study. Participation in DISCOVER may have caused some healthcare practitioners to make different treatment decisions than they would if the data were not being recorded. Given that participants enrolled in DISCOVER were all initiating second-line glucose-lowering therapy, our findings may also not be representative of the entire type 2 diabetes population and may overestimate the proportion of older individuals who are inappropriately strictly managed. Given their involvement in DISCOVER, participating physicians and sites may also be more focused on quality of care than others. This may have resulted in an over-representation of more advanced treatment centers. In line with the observational nature of the study, there was no requirement to record all study variables and a complete data set was not available for all patients. Although these analyses highlight a subset of patients whose treatments are inappropriately intensive, associations between intensive glycemic control and potential adverse effects related to severe hypoglycemia could not be assessed due to the limited follow-up time. Of note, only a small number of participants experienced major hypoglycemic events during the first 12 months after baseline (no participants among those receiving inappropriate treatment intensification at baseline but no high-risk medication and three participants among those receiving inappropriate treatment intensification at baseline and high-risk medications; data not shown). Finally, our definition of an inappropriately intensive glucose-lowering treatment in this older population was based on an $\mathrm{HbA}_{1 \mathrm{c}}$ level of $<7.0 \%$, in line with $\mathrm{ADA}$ guidelines, which recommend an $\mathrm{HbA}_{1 \mathrm{c}}$ level of $<7.5 \%$ in older patients. However, lower $\mathrm{HbA}_{1 c}$ targets may be appropriate for some of these patients. For example, patients early in the disease process, who are otherwise healthy without comorbidities, may benefit from initial tight glycemic control to reduce the risk of microvascular complications and may have been misclassified as being inappropriately tightly controlled. ${ }^{1}$

To conclude, in a global cohort of patients with type 2 diabetes initiating second-line glucose-lowering therapy, we found that $23.5 \%$ of older patients treated in routine clinical practice are potentially receiving an inappropriately intensive treatment, leaving them at an increased risk of polypharmacy and possible downstream complications, such as severe hypoglycemia. This proportion of patients increased to more than $50 \%$ during follow-up, with substantial variation between regions. Overall, up to one-third of these patients, or more in lower-middle-income and upper-middle-income countries, received treatment with high-risk glucose-lowering medication, potentially leaving them at an even greater risk of hypoglycemia. This highlights the inequality of type 2 diabetes care across the globe and also the need for a more personalized approach to treatment of type 2 diabetes in older patients, with a greater consideration of the benefit to risk ratio of intensive glycemic control. Future analyses could provide information on outcomes associated with inappropriate treatment intensifications and the possible benefits and harms of complex treatment regimens and treatment with high-risk medications and could complement results from interventional studies. 
Author affiliations

${ }^{1}$ Institute for Biometrics and Epidemiology, German Diabetes Center Leibniz Institute for Diabetes Research at Heinrich Heine University Düsseldorf, Dusseldorf, Germany

${ }^{2}$ Saint Luke's Mid America Heart Institute, Kansas City, Missouri, USA

${ }^{3}$ University of Missouri Kansas City, Kansas City, Missouri, USA

${ }^{4}$ Department of Endocrinology, University of Nantes, Paris, France

${ }^{5}$ AstraZeneca, Gaithersburg, Maryland, USA

${ }^{6}$ AstraZeneca, Cambridge, UK

${ }^{7}$ Internal Medicine, Rio de Janeiro State University, Rio de Janeiro, Brazil

${ }^{8}$ Department of Endocrinology and Metabolism, Peking University People's Hospital,

Beijing, China

${ }^{9}$ Leicester Diabetes Centre, University of Leicester, Leicester, UK

${ }^{10}$ AstraZeneca, Madrid, Spain

${ }^{11}$ Center for Outcomes Research and Clinical Epidemiology, Pescara, Italy

${ }^{12}$ Endocrinology Research Centre, Moscow, Russian Federation

${ }^{13}$ Osaka University School of Medicine Graduate School of Medicine, Suita, Japan

${ }^{14}$ Juntendo University School of Medicine Graduate School of Medicine, Bunkyo-ku Japan

Acknowledgements The authors would like to thank all the patients and investigators participating in the DISCOVER study program. Medical writing support was provided by Steph Macdonald, PhD, of Oxford PharmaGenesis, Oxford, UK, and was funded by AstraZeneca.

Contributors BB, SVA, BHC, HC, AC, PF, MG, LJ, KK, MK, JM, AN, MS, IS, FT, HW, and WR agreed on the general content of the manuscript. BB, WR, HC, and FT developed the statistical analysis plan, which was conducted by $\mathrm{HC}$ and $\mathrm{FT}$. The first draft of the manuscript was developed by BB, and WR, SVA, BHC, HC, AC, PF, MG, LJ, KK, MK, JM, AN, MS, IS, FT, and HW contributed to its development. BB, SVA, BHC, HC, AC, PF, MG, LJ, KK, MK, JM, AN, MS, IS, FT, HW, and WR approved the final version of the manuscript before its submission. An AstraZeneca team reviewed the manuscript during its development and was given the opportunity to make suggestions. However, the final content was determined by BB, SVA, BHC, $\mathrm{HC}, \mathrm{AC}, \mathrm{PF}, \mathrm{MG}, \mathrm{LJ}, \mathrm{KK}, \mathrm{MK}, \mathrm{JM}, \mathrm{AN}, \mathrm{MS}$, IS, FT, HW, and WR. BB and WR are the guarantors of this work.

Funding The DISCOVER study program is funded by AstraZeneca. DISCOVER is a non-interventional study program, and no drugs were supplied or funded. All statistical analyses were funded by AstraZeneca and conducted, independently of the study sponsor, by the statistical group at Saint Luke's Mid America Heart Institute, Kansas City, Missouri, USA.

Competing interests BHC, MG, LJ, KK, MK, AN, MS, IS, HW, and WR are members of the DISCOVER Scientific Committee and received financial support from AstraZeneca to attend DISCOVER planning and update meetings. BB and SVA have no competing interests to disclose. $\mathrm{HC}, \mathrm{AC}, \mathrm{PF}$, and JM are employees of AstraZeneca. In addition, BHC has received payment from AstraZeneca, Boehringer Ingelheim, Lilly, Merck Sharp \& Dohme, Novartis, Novo Nordisk, Sanofi, and Takeda. MG has received honoraria from Merck Serono. LJ has received honoraria from AstraZeneca, Bayer, Boehringer Ingelheim, Bristol-Myers Squibb, Eli Lilly, Merck Sharp \& Dohme, Novartis, Novo Nordisk, Takeda, Sanofi, and Roche; and research support from AstraZeneca, Bristol-Myers Squibb, Eli Lilly, Merck Sharp \& Dohme, Novartis, Roche, and Sanofi. KK has received honoraria from AstraZeneca, Boehringer Ingelheim, Eli Lilly, Janssen, Merck Sharp \& Dohme, Novartis, Novo Nordisk, Sanofi, Takeda, Servier, and Pfizer; research support from AstraZeneca, Boehringer Ingelheim, Eli Lilly, Merck Sharp \& Dohme, Novartis, Novo Nordisk, Sanofi, and Pfizer; and also acknowledges support from the National Institute for Health Research Collaboration for Leadership in Applied Health Research and CareEast Midlands (NIHR CLAHRC-EM) and the NIHR Applied Research Collaboration and the Leicester Biomedical Research Centre. MK has received honoraria from Amgen, Applied Therapeutics, AstraZeneca, Bayer, Boehringer Ingelheim, Eisai, GlaxoSmithKline, Glytec Systems, Intarcia, Janssen, Merck (Diabetes), Novartis, Novo Nordisk, and Sanofi; and research support from AstraZeneca and Boehringer Ingelheim. AN has received honoraria from AstraZeneca, Eli Lilly, Medtronic, and Novo Nordisk; and research support from Artsana, Dexcom, Novo Nordisk, and Sanofi. MS has received honoraria from AstraZeneca, Boehringer Ingelheim, Eli Lilly, Merck Sharp \& Dohme, Novo Nordisk, Sanofi, and Servier; and research support from Novo Nordisk and Sanofi. IS has received honoraria from Astellas Pharma, AstraZeneca, Boehringer Ingelheim, Kowa Pharmaceuticals America, Merck Sharp \& Dohme, Mitsubishi Tanabe Pharma, Novo Nordisk, Ono Pharmaceutical, Sanwa Kagaku Kenkyusho, and Takeda; and research support from Astellas Pharma, AstraZeneca, Daiichi Sankyo, Eli Lilly, Japan Foundation for
Applied Enzymology, Japan Science and Technology Agency, Kowa Pharmaceuticals America, Kyowa Hakko Kirin, Midori Health Management Center, Mitsubishi Tanabe Pharma, Novo Nordisk, Ono Pharmaceutical, Sanofi, Suzuken Memorial Foundation, and Takeda. HW has received honoraria from Astellas Pharma, AstraZeneca, Boehringer Ingelheim, Daiichi Sankyo, Sumitomo Dainippon Pharma, Eli Lilly, Kissei Pharmaceutical, Kowa Pharmaceuticals America, Kyowa Hakko Kirin, Merck Sharp \& Dohme, Mitsubishi Tanabe Pharma, Novartis, Novo Nordisk, Ono Pharmaceutical, Sanofi, Sanwa Kagaku Kenkyusho, and Takeda; and research support from Abbott, Astellas Pharma, AstraZeneca, Bayer, Benefit One Health Care, Boehringer Ingelheim, Bristol-Myers Squibb, Daiichi Sankyo, Dainippon Sumitomo Pharma, Eli Lilly, Johnson \& Johnson, Kissei Pharmaceutical, Kowa Pharmaceuticals America, Kyowa Hakko Kirin, Merck Sharp \& Dohme, Mitsubishi Tanabe Pharma, Mochida Pharmaceutical, Nitto Boseki, Novartis, Novo Nordisk, Ono Pharmaceutical, Pfizer, Sanofi, Sanwa Kagaku Kenkyusho, Taisho Toyama Pharmaceutical, Takeda, and Terumo. FT is an employee of the Mid America Heart Institute and has received research support from AstraZeneca. WR has received research support from Novo Nordisk.

\section{Patient consent for publication Not required.}

Ethics approval The study protocols were approved by the relevant clinical research ethics committees in each country and institutional review boards at each site (online supplemental appendix table 1), and complied with the Declaration of Helsinki, the International Conference on Harmonization Guideline for Good Clinical Practice, and the local regulations for clinical research.

Provenance and peer review Not commissioned; externally peer reviewed.

Data availability statement Data underlying the findings described in this manuscript may be obtained in accordance with AstraZeneca's data sharing policy described at https://astrazenecagrouptrials.pharmacm.com/ST/Submission/ Disclosure.

Supplemental material This content has been supplied by the author(s). It has not been vetted by BMJ Publishing Group Limited (BMJ) and may not have been peer-reviewed. Any opinions or recommendations discussed are solely those of the author(s) and are not endorsed by BMJ. BMJ disclaims all liability and responsibility arising from any reliance placed on the content. Where the content includes any translated material, BMJ does not warrant the accuracy and reliability of the translations (including but not limited to local regulations, clinical guidelines, terminology, drug names and drug dosages), and is not responsible for any error and/or omissions arising from translation and adaptation or otherwise.

Open access This is an open access article distributed in accordance with the Creative Commons Attribution Non Commercial (CC BY-NC 4.0) license, which permits others to distribute, remix, adapt, build upon this work non-commercially, and license their derivative works on different terms, provided the original work is properly cited, appropriate credit is given, any changes made indicated, and the use is non-commercial. See: http://creativecommons.org/licenses/by-nc/4.0/.

\section{ORCID iDs}

Brenda Bongaerts http://orcid.org/0000-0003-4695-7185

Wolfgang Rathmann http://orcid.org/0000-0001-7804-1740

\section{REFERENCES}

1 American Diabetes Association. 12. Older Adults: Standards of Medical Care in Diabetes-2020. Diabetes Care 2020;43:S152-62.

2 Chinese Diabetes Society. Chinese guidelines for type 2 diabetes prevention (2013). Chin J Diabetes 2014;22:2-42.

3 International Diabetes Federation. Global guideline for type 2 diabetes. Available: https://www.idf.org/e-library/guidelines/79 global-guideline-for-type-2-diabetes.html [Accessed 31 Jan 2019].

4 Davies MJ, D'Alessio DA, Fradkin J, et al. Management of hyperglycemia in type 2 diabetes, 2018. A consensus report by the American diabetes association (ADA) and the European association for the study of diabetes (EASD). Diabetes Care 2018;41:2669-701.

5 Garber AJ, Abrahamson MJ, Barzilay Jl, et al. AACE/ACE comprehensive diabetes management algorithm 2015. Endocr Pract 2015;21:438-47.

6 Qaseem A, Barry MJ, Humphrey LL, et al. Oral pharmacologic treatment of type 2 diabetes mellitus: a clinical practice guideline update from the American College of physicians. Ann Intern Med 2017:166:279-90.

7 Schernthaner G, Schernthaner-Reiter MH. Diabetes in the older patient: heterogeneity requires individualisation of therapeutic strategies. Diabetologia 2018;61:1503-16. 
8 Hambling CE, Khunti K, Cos X, et al. Factors influencing safe glucose-lowering in older adults with type 2 diabetes: a personcentred approach to individualised (proactive) glycemic goals for older people: a position statement of primary care diabetes Europe. Prim Care Diabetes 2019;13:330-52.

9 Malabu UH, Vangaveti VN, Kennedy RL. Disease burden evaluation of fall-related events in the elderly due to hypoglycemia and other diabetic complications: a clinical review. Clin Epidemiol 2014;6:287-94.

10 Whitmer RA, Karter AJ, Yaffe K, et al. Hypoglycemic episodes and risk of dementia in older patients with type 2 diabetes mellitus. JAMA 2009;301:1565-72.

11 Kosiborod M, Gomes MB, Nicolucci A, et al. Vascular complications in patients with type 2 diabetes: prevalence and associated factors in 38 countries (the discover study program). Cardiovasc Diabetol 2018;17:150.

12 Bonds DE, Miller ME, Bergenstal RM, et al. The association between symptomatic, severe hypoglycaemia and mortality in type 2 diabetes: retrospective epidemiological analysis of the Accord study. BMJ 2010;340:b4909.

13 Peron EP, Ogbonna KC, Donohoe KL. Antidiabetic medications and polypharmacy. Clin Geriatr Med 2015;31:17-27.

14 Rodriguez-Poncelas A, Barrot-de la-Puente J, Coll de Tuero G, et al. Glycaemic control and treatment of type 2 diabetes in adults aged 75 years or older. Int J Clin Pract 2018;72:e13075.

15 Arnold SV, Lipska KJ, Wang J, et al. Use of intensive glycemic management in older adults with diabetes mellitus. J Am Geriatr Soc 2018;66:1190-4.

16 Hambling CE, Seidu SI, Davies MJ, et al. Older people with type 2 diabetes, including those with chronic kidney disease or dementia are commonly overtreated with sulfonylurea or insulin therapies. Diabet Med 2017;34:1219-27.

17 Müller N, Khunti K, Kuss O, et al. Is there evidence of potential overtreatment of glycaemia in elderly people with type 2 diabetes? data from the guidance study. Acta Diabetol 2017;54:209-14

18 Lipska KJ, Ross JS, Miao Y, et al. Potential overtreatment of diabetes mellitus in older adults with tight glycemic control. JAMA Intern Med 2015;175:356-62.
19 Zaccardi F, Davies MJ, Dhalwani NN, et al. Trends in hospital admissions for hypoglycaemia in England: a retrospective, observational study. Lancet Diabetes Endocrinol 2016;4:677-85.

20 Ji L, Bonnet F, Charbonnel B, et al. Towards an improved global understanding of treatment and outcomes in people with type 2 diabetes: rationale and methods of the discover observational study program. J Diabetes Complications 2017;31:1188-96.

21 Katakami N, Mita T, Takahara M, et al. Rationale and design for the J-DISCOVER study: discovering the treatment reality of type 2 diabetes in a real-world setting in Japan-A protocol. Diabetes Ther 2018;9:165-75

22 United Nations Department of Economic and Social Affairs. World population ageing, 2019. Available: https://www.un.org/en/ development/desa/population/publications/pdf/ageing/WorldPopulat ionAgeing2019-Highlights.pdf [Accessed 13 Feb 2020].

23 Wojszel ZB, Kasiukiewicz A. A retrospective cross-sectional study of type 2 diabetes overtreatment in patients admitted to the geriatric ward. BMC Geriatr 2019;19:242.

24 Noale M, Veronese N, Cavallo Perin P, et al. Polypharmacy in elderly patients with type 2 diabetes receiving oral antidiabetic treatment. Acta Diabetol 2016:53:323-30.

25 Chow CK, Ramasundarahettige C, Hu W, et al. Availability and affordability of essential medicines for diabetes across highincome, middle-income, and low-income countries: a prospective epidemiological study. Lancet Diabetes Endocrinol 2018;6:798-808.

26 Bazargani YT, de Boer A, Leufkens HGM, et al. Selection of essential medicines for diabetes in low and middle income countries: a survey of 32 national essential medicines Lists. PLoS One 2014;9:e106072.

27 Gomes MB, Rathmann W, Charbonnel B, et al. Treatment of type 2 diabetes mellitus worldwide: baseline patient characteristics in the global discover study. Diabetes Res Clin Pract 2019;151:20-32.

28 Dobrică E-C, Găman M-A, Cozma M-A, et al. Polypharmacy in type 2 diabetes mellitus: insights from an internal medicine department. Medicina 2019;55:436.

29 Budnitz DS, Lovegrove MC, Shehab N, et al. Emergency hospitalizations for adverse drug events in older Americans. $N$ Engl J Med 2011;365:2002-12.

30 Lipska KJ, Ross JS, Wang Y, et al. National trends in US hospital admissions for hyperglycemia and hypoglycemia among Medicare beneficiaries, 1999 to 2011. JAMA Intern Med 2014;174:1116-24. 